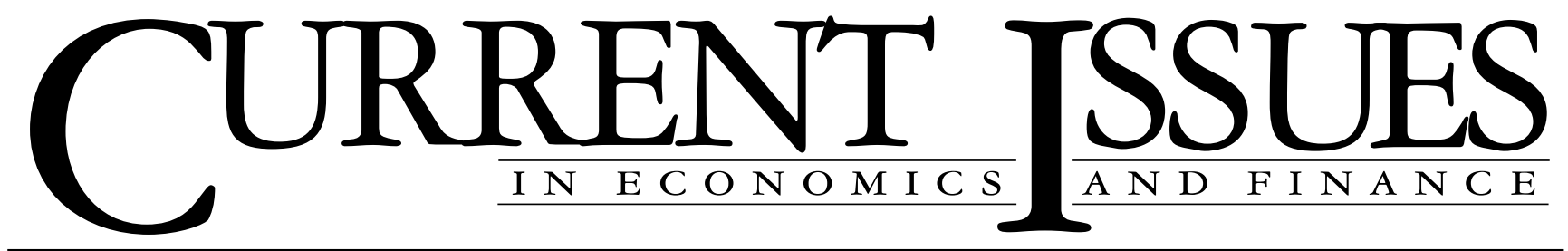

December 1995

Volume 1 Number 9

\title{
Chain-weighting: The New Approach to Measuring GDP
}

\author{
Charles Steindel
}

Recent dramatic changes in the U.S. economy's structure have compelled BEA to revise the way in which it measures real GDP levels and growth. By switching to a chain-weighted method of computing aggregate growth - which relies heavily on current price informationBEA will be able to measure GDP growth more accurately by eliminating upward biases in the incoming data.

The U.S. Department of Commerce's Bureau of Economic Analysis (BEA) is changing its method of measuring the growth of the U.S. economy. Shifts in the structure of the economy-particularly the spectacular fall in computer prices-have meant that BEA's traditional "fixed-base-year" method of tracking the nation's gross domestic product (GDP) has tended to overstate growth in recent years. As a result, BEA is using a new, "chain-weighted" procedure to measure GDP growth more accurately. ${ }^{1}$ In mid-December, BEA plans to release newly revised data, based on this procedure, for the post-1992 period. ${ }^{2}$

BEA's decision to revise its technical procedures has generated considerable controversy. Some observers are uneasy about the looming reductions in estimates of recent GDP growth; others are concerned about the repercussions of the change for economic analysis and forecasting.

This edition of Current Issues takes a close look at the shift in BEA's procedures. It outlines the traditional technique for measuring GDP and the problems that have led to the new procedure, and touches briefly on the mechanics of the chain-weighted method. The article also responds to criticisms of chain-weighting and speculates on the shift's implications for policy analysis. ${ }^{3}$

\section{The Traditional Fixed-Base-Year Method}

The economy consists of millions of individuals and firms producing a multitude of goods and services. This complexity virtually ensures that any method of estimating "real GDP" involves making some more or less arbitrary decision about the most appropriate way to add up data from individual sectors. Since about the time of World War II, BEA has used the fixed-baseyear aggregation technique to estimate real GDP. This technique involves using the prices of a particular base year (currently 1987) to value physical, or real, production in each sector of the economy and summing the sectoral base year values to arrive at an overall figure for real GDP. The growth of real GDP is then calculated as the periodic change in this aggregate.

Unfortunately, a major fault with this traditional method is that in periods of substantial economic change it results in BEA growth estimates that are highly sensitive to the arbitrary choice of the base year. However, despite this fault, the traditional procedure has the virtues of simplicity and long-established use. Moreover, it results in a real GDP measure that equals the sum of its parts: real GDP exactly comprises real consumption, real investment, real government spending, and real net exports. Thus, with fixed-base-year data, it is easy to gauge a sector's share of overall economic activity. 


\section{Problems with the Traditional Method}

Given these advantages, why is the fixed-base-year procedure being abandoned? One reason is that it implies that aggregate real GDP can be arbitrarily changed by shifts in output composition. An extreme example illustrates this phenomenon. Consider two products: computers and the economist's favorite, widgets. Assume that widgets are made of the same materials as computers and require the same amount of labor to assemble. In 1987, computers cost more to buy than widgets, but in 1995 one widget sells for the same price as one computer. Suppose the owner of a widget factory decides in 1995 to change production to computers by simply switching a knob. Has aggregate real output increased? Surely not. Nothing in particular has changed, except that the boxes coming off the assembly line are now labeled "computers" rather than "widgets."

However, BEA's statisticians, seeing the switch in the factory's production and applying the fixed-baseyear technique, note an increase in the value of the factory's output in 1987 dollars and decide that the switch has increased real GDP. If the change had been made in 1987, the reported increase in real output would have been reasonable because the factory switched to making what was then a more valuable product. However, registering the 1995 switch as an output gain makes little sense given that computers and widgets sell for the same price in 1995 . There is no objective measure indicating that manufacturing computers in 1995 is a more productive activity than manufacturing widgets.

\section{Chart 1}

\section{Computer Prices Have Plunged While Spending} Has Surged

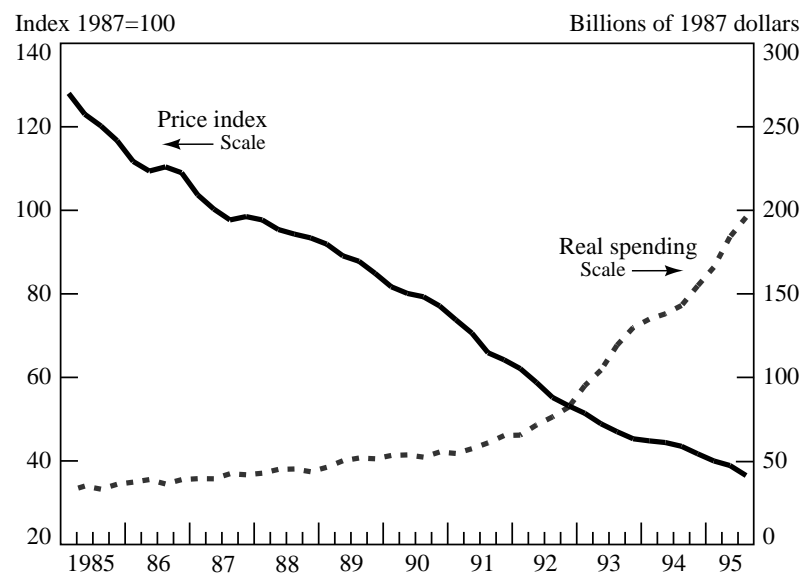

Source: U.S. National Income and Product Accounts.

Notes: The price index is the deflator for producers' durable office, computing, and accounting machinery spending; the average decline in the price index for $1985-95$ was 11.0 percent. Real spending is producers' durable goods outlays on office, computing, and accounting machinery; the average growth in real spending for 1985-95 was 20.9 percent.
We see, then, that with the traditional procedure, the measurement of aggregate real output depends not only on the distribution of production by sector, but also on the distribution of prices by sector in the base year.

This drawback leads to a second problem: With the fixed-base-year method, historical data on aggregate

\section{A major fault with [the fixed-base-year] method is that in periods of substantial economic change it results in BEA growth estimates that are highly sensitive to the arbitrary choice of the base year.}

GDP growth rates are changed when the base year is shifted because the distribution of prices by sector changes. If the relative price of a sector's output is lower in a new base year than in the previous one, the sector will represent a smaller part of real GDP for each year of the historical series. Growth of the sector will therefore be reported to play a less important role in the growth of aggregate real GDP. Because there is no guarantee that greater contributions from other sectors will precisely make up for this loss, there is no guarantee that aggregate growth will not change when a base year is switched. In short, the entire history of real GDP growth changes each time the base year is switched. (As the box shows, one can in principle get a wide range of estimates of aggregate growth over periods by changing base years.)

Although BEA has always acknowledged these problems, they have gained greater urgency in recent years because of the spectacular fall in computer prices (Chart 1). Consequently, each time the GDP base year has been moved forward-recently from 1972 to 1982 to 1987 - both the share of the computer industry in real GDP and the contribution of the rapidly expanding computer industry to GDP growth have dropped sharply. Past shifts in the base year have resulted in noticeable cuts in the historic data on GDP growth for recent years. For example, BEA has estimated that shifting the base year from 1982 to 1987 resulted in an average drop of 0.3 percentage point in GDP growth for 1982-88 (Young 1989). This adjustment is not trivial; for instance, it is close to some economists' estimates that the decline in U.S. saving-including the increase in the budget deficit-cut U.S. growth rates by an average of 0.5 percent in the $1980 \mathrm{~s}^{4}$

The BEA calculation prompts an important question: Why doesn't BEA avoid rewriting the history of growth by simply freezing the base year? 


\section{Box: Comparing Fixed-Base-Year and Chain-weighted GDP Growth}

Suppose the economy produces only two products: potato chips and computers. As panel 1 of the table shows, potato chip production rises slowly from 1977 to 1992 , while the price rises from $\$ 2.00$ to $\$ 3.50$. Computer production and prices behave very differently, with production doubling and prices falling by 50 percent every five years.

\section{Fixed-Base-Year Measures}

How, then, should overall growth be measured? Suppose we measure real GDP using the fixed-baseyear method, with 1977 as the base year. The production of potato chips and computers will be valued according to 1977 prices and summed (panel 2). In 1977 dollars, real GDP will grow 40 percent between 1977 and 1982, 52.4 percent between 1982 and 1987, and 65.6 percent between 1987 and 1992 (panel 3, column 1).

Now suppose real GDP is based on 1982 prices. The change in the base year will substantially reduce our estimate of overall growth. Cumulative GDP growth drops from 253 percent between 1977 and 1992 in 1977 dollars to 142 percent for the same interval in 1982 dollars (panel 3, row 4). The differences widen even more when real GDP is measured in 1987 and 1992 dollars.

\section{Chain-weighted Measure}

The tremendous divergence in growth estimates invites us to find a compromise. One way is to assume that growth for a period is midway between the rates suggested by the base years that bracket it (in panel 3, the growth rates used to average each period are in bold font). This procedure, a simplification of the chain-weighted technique, ${ }^{*}$ gives growth estimates of 32.5 percent for $1977-82,27.2$ percent for $1982-87$, 23.3 percent for $1987-92$, and a cumulative growth of 107.8 percent for the fifteen years (panel 3, column 5) - near the middle of the range encompassed by the fixed-base-year calculations.

The key advantage of this method over the fixedbase-year technique is that it uses prices from a period to help compute real growth for that period. For instance, on a 1977 base, real output growth in 1987-92 is grossly overstated because computers are valued at their high 1977 price; conversely, on a 1992 base, real output growth in 1977-82 is understated because computers are valued at their low 1992 price.

*A major difference is that the chain-weighted method is applied to annual data, rather than to five-year intervals.

\section{Alternative Computations of Real GDP Growth}

\begin{tabular}{|c|c|c|c|c|}
\hline \multirow[b]{2}{*}{ Year } & \multicolumn{2}{|c|}{ Potato Chips (by Bag) } & \multicolumn{2}{|c|}{ Computers (by Unit) } \\
\hline & Number Produced & Price & Number Produced & Price \\
\hline 1977 & 10,000 & $\$ 2.00$ & 1 & $\$ 10,000$ \\
\hline 1982 & 11,000 & 2.50 & 2 & 5,000 \\
\hline 1987 & 12,000 & 3.00 & 4 & 2,500 \\
\hline 1992 & 13,000 & 3.50 & 8 & 1,250 \\
\hline
\end{tabular}

Panel 2: Real GDP Measured by the Fixed-Base-Year Method (Thousands of Dollars)

\begin{tabular}{lcccc} 
Year & 1977 Prices & 1982 Prices & 1987 Prices & 1992 Prices \\
\hline 1977 & 30.0 & 30.0 & 32.5 & 36.25 \\
1982 & 42.0 & 37.5 & 38.0 & 41.0 \\
1987 & 64.0 & 50.0 & 46.0 & 47.0 \\
1992 & 106.0 & 72.5 & 59.0 & 55.5
\end{tabular}

Panel 3: Growth of Real GDP (Percentage Change)

\begin{tabular}{|c|c|c|c|c|c|}
\hline \multirow[b]{2}{*}{ Period } & \multicolumn{4}{|c|}{ Fixed-Base-Year Measures } & \multirow{2}{*}{$\begin{array}{c}\text { Simplified } \\
\text { Chain-weighted Measure }\end{array}$} \\
\hline & 1977 Prices & 1982 Prices & 1987 Prices & 1992 Prices & \\
\hline $1977-82$ & 40.0 & 25.0 & 16.9 & 13.1 & 32.5 \\
\hline $1982-87$ & 52.4 & 33.3 & 21.1 & 14.6 & 27.2 \\
\hline $1987-92$ & 65.6 & 45.0 & 28.3 & 18.1 & 23.3 \\
\hline $1977-92$ & 253.3 & 141.7 & 81.5 & 53.1 & 107.8 \\
\hline
\end{tabular}


Unfortunately, such a step would just exacerbate the first problem-the switch in output between two similarly priced products that alters measured growth because of differing base-year prices. As the time period from the base year increases, so too will the likelihood of this problem cropping up.

\section{The BEA Solution: Chain-weighted GDP Growth}

To address these problems, BEA will apply its new, chain-weighted method of measuring GDP growth. This involves making two calculations of growth for each year, with the year itself and the preceding year used as bases. Chain-weighted GDP growth for a year

\section{BEA will apply its new, chain-weighted method of measuring GDP growth. This involves making two calculations of growth for each year, with the year itself and the preceding year used as bases.}

is the average of these two growth rates. For instance, BEA will estimate real GDP growth for 1990 by averaging the growth rate computed using 1989 as the base year and the growth rate computed using 1990 as the base year. ${ }^{5}$

The chain-weighted procedure should effectively eliminate the problems associated with the fixed-baseyear method. By continually moving the base year forward rather than using some distant year as a base, BEA can ensure that switches in production between similarly priced items will not distort growth. The chain-weighted procedure will also freeze the historic record of growth. History will no longer be rewritten by an arbitrary switch of the base year-the growth rates for a year will instead remain fixed. ${ }^{6}$

Despite these advantages, the chain-weighted procedure will add considerable complexity to the construction of GDP growth estimates. BEA will, in effect, use every year as a base year. Each base year, however, will only be used to help compute real GDP growth for two years. For instance, growth in GDP in 1990 prices will be used in the computation of real GDP growth in 1990 and 1991, but not in any other year. With the fixedbase-year method, growth in GDP in base-year prices was computed for the entire historical series.

\section{Two Broken Links in the Chain?}

Users of economic data and forecasts have voiced two major concerns about the chain-weighted method. ${ }^{7}$ These concerns are now described and evaluated.
Why Reduce Growth? The chain-weighted procedure will yield estimates of aggregate growth for recent years that are consistently lower than those expressed in 1987 prices (Chart 2). The major reason is that the rapidly growing computer industry, valued in 1987 prices, claims a higher share of output and hence contributes more to growth than it does under the chainweighted procedure. With chain-weighting, a sector's growth contribution depends on its current prices, and as Chart 1 shows, computers cost far less today than they did in 1987. Larger growth contributions from other sectors will not compensate for computers' reduced contribution. Critics of chain-weighting point out that not only will overall growth be reduced, but estimates of productivity growth-or output per worker-will also be cut. In short, there will be much less evidence that productivity growth in the 1990s has surpassed the disappointing rates of the 1980s.

These critics find the anticipated reduction in announced growth to be quite troubling. They contend that it will give misleading indications of the true state of the economy. ${ }^{8}$ Their view is that high technology is triggering a growth spurt and an improved productivity trend, both of which should be reflected in the aggregate data. They also contend that BEA is concentrating on a technical problem while disregarding a more fundamental problem-namely, the underestimation of growth in individual sectors that may stem from overstatements of inflation. From their perspective, if both the technical faults of the fixed-base-year procedure and systematic undercounts of growth cannot be corrected at the same time, why not leave well enough alone?

Although many observers believe that high technology is making profound changes to the economy, there

\section{Chart 2 \\ Calculating Real GDP Growth Using Fixed-Base-Year and Chain-weighted Methods}

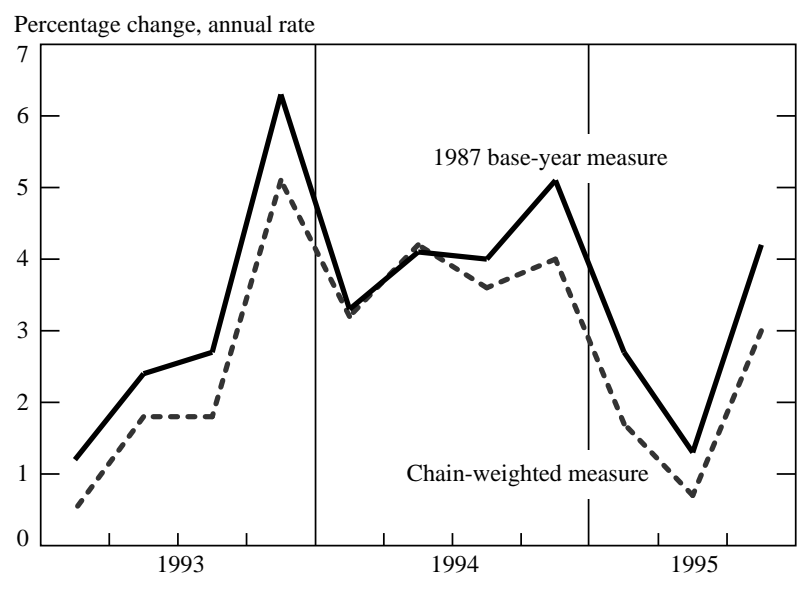

Source: U.S. National Income and Product Accounts. 
is surprisingly little quantitative evidence that it is setting off an aggregate growth spurt. ${ }^{9}$ Furthermore, recent growth rates would be reduced even if BEA simply moved its base year from 1987 to 1992, rather than switched to the chain-weighted method. It is hard to support the argument that BEA should continue to measure GDP in 1987 dollars simply to report higher growth rates.

Shouldn't the Whole Equal the Sum of Its Parts? A second area of concern centers on the failure of the chain-weighted procedure to permit the construction of a time series of real GDP that equals the sum of its parts. ${ }^{10}$ As a result, we will no longer see real GDP, expressed in prices of a certain year, as the exact sum of real consumption, real investment, real government spending, and real net exports. The inability to decompose the level of aggregate GDP in a simple fashion will mean, for example, that we can no longer measure precisely manufacturing's share of real GDP. In addition, the loss of a simple method of decomposing GDP will mean significant technical changes in the production of economic forecasts and some reeducation for forecasters.

Although doing without this simple sum relationship could be disconcerting, the practical cost may be small. For example, while we will not be able to measure precisely manufacturing's share of overall real GDP, we will still be able to gauge the importance of growth in manufacturing to overall growth. ${ }^{11}$

\section{Policy Implications}

The new method of measuring real GDP growth should have little impact on policy analysis of the macroeconomy. The new data will show that the economy has been growing a bit less rapidly over the last few years than we had thought. Folding these data into longer term information on economic growth will probably cause a modest downward adjustment to estimates of potential growth and, in turn, paint a slightly more pessimistic picture of developments in the 1990s relative to recent decades. (Similar changes would also occur if BEA retained the fixed-base-year method and moved the base year from 1987 to 1992.)

Most important, the new data should not alter any estimates of the effects of monetary and fiscal policy on inflation, employment, and the budget and trade deficits. Key data on inflation, such as the consumer and producer price indexes, will not be changed, nor will the data on employment or the budget and trade deficits. ${ }^{12}$ With the inflation, employment, and deficit data unchanged, existing estimates of policy effects should still hold. Nevertheless, the chain-weighted procedure will change estimates of policy effects on GDP growth, as well as estimates of the effect of GDP growth on inflation, employment, and the budget and trade deficits.

On the whole, the most significant consequences of the revised GDP measurement system may be that growth in recent years will be marked down and the chronic upward bias to ongoing estimates of aggregate growth eliminated. These changes should alter estimates of the effects of policy on longer term growth and lessen any tendency to overstate the strength of the economy by focusing on incoming data.

\section{Conclusion}

BEA is phasing out its traditional fixed-base-year method of calculating real GDP levels and growth. Recent dramatic changes in the structure of the economy have underscored the need for a new method of measurement.

BEA has responded to this need by switching to a chain-weighted method of computing aggregate growth that relies heavily on current price information. Although this switch complicates the estimation process and involves the abandonment of an easily computed and defined level of real GDP, it will effectively eliminate upward biases to growth in the incoming data. In addition, the new procedure should have only a limited effect on economic policy analysis: while it could influence the analysis of longer term growth, it should not alter estimates of the inflation and employment effects of policy.

The switch to chain-weighting is an event of considerable importance to economic forecasters because it will change the way in which they make predictions. For others-policymakers included-the change will be less significant. However, it should mean that at the time of initial release, GDP data will give a more reliable picture of economic growth than they did in the past.

\section{Notes}

1. Information on the fixed-base-year measure will still be issued, but the timeliness and depth of detail will be less than in the past.

2. BEA has tentatively scheduled the release of revised data for 1959-92 for early December.

3. The switch to the chain-weighted procedure is only one part of a comprehensive revision of GDP data. Newly available data on many sectors of the economy will be incorporated in the National Income and Product Accounts, and there will be some definitional changes. The net effect of these changes on aggregate growth is presently unknown. Consequently, this article considers the effects of the switch to chain-weighting apart from any other changes in the data. 
4. Harris and Steindel (1991) estimate that the decline in U.S. saving in the 1980s reduced the level of 1990 potential GDP by 5 percent; this drop would roughly correspond to a 0.5 percentage point reduction in the annual average growth of GDP in the decade.

5. The text simplifies the actual procedure slightly. For more technical information on the procedure, see Landefeld (1995), Landefeld and Parker (1995), Young (1989), and Triplett (1992).

6. The historic record of GDP growth could still be altered by incorporating more complete information on individual sectors of the economy. Because incoming data are often incomplete, the chainweighted procedure cannot be strictly applied to the most recent figures, and revisions will probably be required. For example, complete 1994 and 1995 data are necessary to make a precise calculation of chain-weighted 1995 growth.

7. Other technical wrinkles to the chain-weighted procedure involve matters such as the construction of quarterly estimates and the treatment of inventories, which are of great interest to builders of economic forecasts. For a discussion of these issues, see Laurence H. Meyer \& Associates (1995) and Lasky (1995).

8. For instance, see Roach (1995) and Spiers (1995).

9. For a discussion of this issue, see Oliner and Sichel (1994).

10. The chain-weighted procedure fixes permanently both the aggregate real GDP growth rate for a year and the growth of individual components. A series whose growth bears a fixed relationship to the growth of its components cannot in general be reexpressed to equal the sum of the components.

11. BEA will release real GDP data in 1992 dollars, constructed by extrapolating nominal GDP in 1992 by the chain-weighted growth for the total and its components. For recent years, the new 1992 dollar real GDP aggregate will be very close to the simple sum of its parts (Landefeld and Parker 1995). However, as we move away from 1992, the discrepancy between the 1992 dollar total and the sum of the 1992 dollar components will become considerably larger.

12. The GDP deflator will change substantially, but this indicator has never been considered a useful measure of inflation. The revised series, for technical reasons, could be considered a good guide to economy-wide inflation.

\section{References}

Harris, Ethan S., and Charles Steindel. 1991. "The Decline in U.S. Saving and Its Implications for Economic Growth." Federal Reserve Bank of New York Quarterly Review, 15, no. 3-4.

Landefeld, J. Steven. 1995. "BEA's Featured Measure of Output and Prices." National Association of Business Economists News, no. 113 (September).

Landefeld, J. Steven, and Robert P. Parker. 1995. "Preview of the Comprehensive Revision of the National Income and Product Accounts: BEA's New Featured Measures of Output and Prices." Survey of Current Business, 75 (July).

Lasky, Mark J. 1995. "A Preview of the New Chain-Weighted GDP Measures." DRI/McGraw Hill U.S. Review, September.

Laurence H. Meyer \& Associates. 1995. "Macro Modeling \& Forecasting with Chain-Type Measures of GDP." Special Report, August 29.

Oliner, Stephen D., and Daniel Sichel. 1994. "Computers and Output Growth Revisited: How Big is the Puzzle?" Brookings Papers on Economic Activity, no. 2.

Roach, Stephen S. 1995. "Unchained Melody." Barron's, September 4.

Spiers, Joseph. 1995. "Why Can't the U.S. Measure Productivity Right?” Fortune, October 16, p. 55.

Triplett, Jack E. 1992. "Economic Theory and BEA's Alternative Quantity and Price Indexes." Survey of Current Business, 72 (April).

Young, Allan H. 1989. "Alternative Measures of Real GDP." Survey of Current Business, 69 (April).

\section{About the Author}

Charles Steindel is a vice president in the Domestic Research Function of the Research and Market Analysis Group.

The views expressed in this article are those of the author and do not necessarily reflect the position of the Federal Reserve Bank of New York or the Federal Reserve System.

Current Issues in Economics and Finance is published by the Research and Market Analysis Group of the Federal Reserve Bank of New York. Dorothy Meadow Sobol is the editor.

Editorial Staff: Valerie LaPorte, Mike De Mott, Elizabeth Miranda

Production: Graphics and Publications Staff

Subscriptions to Current Issues are free. Write to the Public Information Department, Federal Reserve Bank of New York, 33 Liberty Street, New York, N.Y. 10045-0001, or call 212-720-6134. Back issues are also available. 